\title{
10 Steps to Organize Research Paper
}

\section{Kshitij Shinghal ${ }^{*}$}

Associate Professor and Dean Academics, Department of Electronics and Communication, MIT, Moradabad, Uttar Pradesh, India

Being a part of the Editorial Board of this esteemed journal, I acknowledge the contribution of the entire author's, reviewers, editors and other team members of the journal. I am thankful to all contributors for submitting their valuable research works. Knowing one's own interest is not an easy goal to achieve with perfection though. However, a researcher in the domain of biosensors and bioelectric should develop intense interest in studying the impact and applications of engineering, science and technology in research, design, development and challenges in the field of biosensors and bioelectronics. A young researcher's mind is like a closed pot when it is not exposed to outside world/peers for interaction, critical analysis and feedback. The "Journal of Biosensors \& Bioelectronics" is a very good platform for disseminating research work, ideas and innovations at internationally recognized platform.

Generally, when a young research scholar starts writing a research paper, he is not having any previous experience or due to lack of proper guidance he ends up with incomplete paper or several fragments of paper which he is unable to wind up in coherence. This leads to frustration or forces him to give up writing research paper. Another reason for substantial delays in writing research paper is incorrect sequence of steps followed for organizing research paper. For example, generally first thing which a scholar write is the title of the paper, then abstract, followed by introduction, methodology etc. This approach is just reverse of the correct sequence of organizing a good research paper. Here are the 10 steps, followed to be in chronological order, for successful organization and timely completion of your research paper:

\section{Prepare the Figures and Tables}

Prepare all the figures and tables of data, write their captions, sequence them for proper numbering and citation of references.

\section{Write the Methods}

Write the methodology you followed to study the research problem. Try to include detailed information like simulation or experimental setup details so a fellow researcher can reproduce the experiment. However, do not repeat the details of established and well known methods.

\section{Write up the Results and Discussion}

Obtain the final results of your work (graphs, charts, tables, figures etc.). Get comparison of results done with previous works/results wherever necessary. Discuss the significance and impact of the results.

\section{Write Conclusion and Future Scope of the Work}

Summarize your work clearly. Do not repeat results or abstract in conclusion. Provide a clear scientific justification for your work in this section. Moreover, you can suggest future scope of the work and point out those that are underway.

\section{Write a Compelling Introduction}

Define your research problem clearly, what are the existing approaches to solve the problem, how your approach is better than previous work, what results you hope to achieve, demonstrate the scientific significance of your work etc. Keep introduction concise and to the point. Hypothesis, objectives and organization of paper should be clearly stated at the end of introduction section.

\section{Write the Abstract}

Abstract along with title is the showcase of your research paper. Often it is the deciding factor whether your paper will be considered for publication or not. So, try to make it impressive, interesting and easy to understand without reading whole article. Abstract should clearly depict what is your research paper about and what are the significant results of your paper. Try to keep it as brief as possible within the word limit prescribed by the journal for abstract.

\section{Write a Concise and Descriptive Title}

Write a powerful and impressive title. Try to be precise and specific while writing the title for your paper. Avoid very long titles as long titles distract readers. Title should be clear, descriptive and impressive to attract the readers and create good impression.

\section{Select Keywords}

Select proper keywords for your paper. Keywords are used for indexing and archiving your research paper. Avoid using keywords with a broad meaning and words already included in the title.

\section{Write the Acknowledgements}

In this section acknowledge the contribution of the people who have contributed in preparing the manuscript like proof reading, editing, grammar correction etc., thank your funding agency, the agency giving you a grant or fellowship.

\section{Write up the References}

This is the most tiresome confusing and troublesome task. How to arrange references, how to properly cite them, proper formatting, sequencing etc. But with the help of few free tool the task becomes very easy. Free tools like 'Docear, JabRef makes the task of citing references very easy. You can also use software such as 'End Note or Mendley' to format and cite references in your paper.

Following the above steps, I am sure researchers will be able to successfully write research papers. Theevolving field of Bioelectronics seeks to exploit biology in combination with electronics in a wider context encompassing, for example, biological fuel cells, bionics and biomaterials for information processing, information storage, electronic components and actuators. While trying to maintain consistency within

*Corresponding author: Kshitij Shinghal, Associate Professor and Dean Academics, Department of Electronics and Communication, MIT, Moradabad, Uttar Pradesh, India, Tel: 9411874617; E-mail: kshinghal@gmail.com

Received July 24, 2017; Accepted July 31, 2017; Published August 08, 2017

Citation: Shinghal K (2017) 10 Steps to Organize Research Paper. J Biosens Bioelectron 8: 245. doi: 10.4172/2155-6210.1000245

Copyright: (c) 2017 Shinghal K. This is an open-access article distributed under the terms of the Creative Commons Attribution License, which permits unrestricted use, distribution, and reproduction in any medium, provided the original author and source are credited. 
the scope of the journal, the editors solicit reviews, surveys, technical articles and research papers of relevance to the scope of journal, which describe important new concepts, support understanding of the field or provide important insights into the practical application, manufacture and commercialization of biosensors and bioelectronics.

The Journal of Biosensors \& Bioelectronics has become a recognized platform for learning, disseminating and exchange of ideas by and for professionals in the field of Biosensors \& Bioelectronics research industry. In addition, this journal allows us to move forward in its novel cause of promoting research with a modality which we have been using for over years and with which we are associated with those who know us. It is better to have open access journals in the community! Being open access makes the chances of getting citation of research paper higher than non-open access journals. On the other hand, open access journals are beneficial to the user of under-developed or developing countries, where user cannot pay to read every new article in the field. The continuing success of this journal gives us a sense of pride and achievement. Please contribute articles to this journal in a timely manner, to ensure it gets published timely and becomes part of this important forum for the exchange of ideas and knowledge which will ultimately translate to better technological exchange of information among peers. If you have any questions or comments about the Journal, please contact the Editor board from Journal of Biosensors \& Bioelectronics.

\section{References and Acknowledgements}

I have based this paper on the materials collected from several courses I've attended. It is inspired by many Guidelines for Authors of various journals of OMICS International. Some of this information is also featured in various tutorials available online. In addition, I have consulted several web pages like http://www.jabref.org/,http://www. docear.org/andhttps://scholar.google.co.in/etc.I want to acknowledge Dr. Divya Kumar, Assistant Professor, CSED, MNNIT Allahabad, for hisvaluable insight of the things. I would also like to thank Mr. Amit Saxena and Ms. Deepti Shinghal for theirvaluable support, without their help this article would have been impossible to complete. 